\title{
Simulation of Qualitative Peculiarities of Capillary System Regulation with Cellular Automata Models
}

\author{
G. Knyshov, Ie. Nastenko, V. Maksymenko and O. Kravchuk \\ National M. Amosov Institute of Cardio-Vascular Surgery, \\ Dept. of Computer Sciences and Computational Physiology \\ National Technical University of Ukraine "KPI", Kyiv, \\ Ukraine Faculty of Biomedical Engineering \\ Ukraine
}

\section{Introduction}

Peripheral circulation can be divided in two components: continuous one, which includes continual fluctuation of muscular vessels diameters; and discrete one, which is caused by opening and closing of pre-capillary sphincters causes the activation-deactivation of capillaries. The state of each capillary sphincter depends on concentration of tissues vasodilator metabolites in the neighborhood of this capillary.

Application of Cellular Automata simulation approach allows to study the behavior of separate capillary system as critically self-organized system and to investigate the different types of interaction between muscular arterial vessels and capillary network.

Analysis of clinical data revealed significant difference in oxygen concentration in arterial and venous blood at normal conditions, at blood flow insufficiency conditions, and at hyperdynamic state of system circulation. This causes significant influence on fluctuation properties of capillary network and of tissues oxygen saturation. Depending on the state of system blood flow each capillary opens and closes at different thresholds of concentration of tissues vasodilator metabolites, closely correlated with tissues oxygen content.

Different types of capillary network behavior have been simulated for various heart rhythm disturbances, which cause irregularity of fluctuations of system blood flow.

Results of simulations were collated with clinical data and have a good correspondence with them.

Regulation of peripheral circulation of blood includes its metabolically caused redistribution, stabilization of the main hemodynamic characteristics at the level of microcirculatory units and mass transfer inside them. The final stabilization of blood pressure occurs at the level of arterioles, then in microcirculatory unit performs a countertransport of oxygen and metabolites through the wall of the true capillary and arteriovenous shunting of blood (Chernukh\&Alexandrov, 1984; Rushmer, 1986, e.a.).

The blood flow in arteries is studied in most detail (Achakri e.a. 1994, Cavalcanti \& rsino, 1996; Little, 1989; Rushmer, 1986, e.a.). However, the integral properties of peripheral blood 
circulatory system is not been adequately studied both at the empirical level, and theoretically, using mathematical models.

The aim of this study is to build a model of microcirculatory network in the form of a cellular automaton, based on information about the anatomy and principles of functioning of the system, to investigate its basic static and dynamic properties and to compare the results with the data from clinical investigations.

Despite the highly stable conditions of blood flow in single capillary, the number of active, working (opened) capillaries is variable and is determined by local metabolic activity of tissues. According to the literature (Achakri e.a. 1994; Chernukh, Alexandrov, 1984; Rushmer, 1986, e.a.), duration of active state of the capillary was 20-70s. That's why capillary network is usually described as a highly inertial, homeostatic, conservative system. However the stability of blood flow conditions in a single capillary can be erroneously identified with the constancy of systemic capillary blood flow in general, which does not correspond to the physiological reality. Bacause the quantity of active capillaries is essentially variable.

In accordance with the concepts of nonlinear science (synergetics) concerning to critically self-organized systems (Bak e.a., 1987,1996; Yusupov, Polonnikov, 1998), the capillary network can be considered as a large interactive system functioning at the "edge of chaos", or, following the terminology of (Risk management, 2000), in a "stable disequilibrium". Regulation of tissue blood flow must be as dynamic as possible to maintain the oxygenation of tissue on appropriate level, which can be inherent in systems with a critical selforganization.

From this point of view, a large variability of quantity of active capillaries can be explained from supposition that a large number of them being in near-critical, most sensitive to any influences, states.

Lack of empirical information can be, at least partially, overcome with modern methods of mathematical modeling using cellular automata simulations.

\section{Clinical data analysis}

\subsection{Initial clinical data}

716 obs. collected in intensive care unit (ICU) in 1-2 days after heart valve replacement and/or coronary-aortic bypass grafting (CABG).

The cardiac index $(C I)$, systolic, diastolic, mean $(M A P)$ arterial and central venous $(C V P)$ pressures, systemic vascular resistance index $(S V R I)$, central body temperature, indices of oxygen delivery $\left(\mathrm{IDO}_{2}\right)$ and consumption $\left(\mathrm{IVO}_{2}\right)$, oxygen content in arterial $\left(\mathrm{Co}_{2 a}\right)$ and venous $\left(\mathrm{Co}_{2 v}\right)$, their arterio-venous gradient $\left(\Delta \mathrm{Co}_{2 a v}\right) \mathrm{pHa,v}$ in arterial and venous blood and some other biochemical parameters were studied.

It should be mentioned that in order to provide the comparability of the indices of oxygen transport, they were normalized to the body surface area.

Cardiac index was calculated by the formula (Kaplan, 1979Ream \& Fogdal, 1982, e.a.):

$$
C I=C O / B S A,
$$

where: $C O, 1 / \mathrm{min}$ - cardiac output, $B S A, m^{2}$ - patient body surface area.

Indices of systemic oxygen delivery $\left(\mathrm{IDO}_{2}\right)$ and consumption $\left(\mathrm{IVo}_{2}\right)$ normalized to body surface area $\left(\mathrm{ml} /\left(\mathrm{min} \bullet \mathrm{m}^{2}\right)\right)$ and calculated by the formulas (Reeder, 1986; Samsel \& Shumacker, 1981, e.a.): 


$$
\begin{gathered}
\mathrm{IDO}_{2}=\mathrm{Co}_{2 \mathrm{a}} \bullet \mathrm{CI} ; \\
\mathrm{IVO}_{2}=\left(\mathrm{Co}_{2 a}-\mathrm{Co}_{2 v}\right) \cdot \mathrm{CI},
\end{gathered}
$$

Where: $\mathrm{CI}, \mathrm{l} /\left(\mathrm{min} \bullet \mathrm{m}^{2}\right)$ - cardiac index; $\mathrm{Co}_{2 \mathrm{a}}, \mathrm{ml} / \mathrm{dl}$ - oxygen content in arterial blood; $\mathrm{Co}_{2 \mathrm{v}}$, $\mathrm{ml} / \mathrm{dl}$ - oxygen content in venous blood.

Oxygen content (concentration) in arterial and venous blood were determined by the equations (Naylor-Sheferd e.a., 1990):

$$
\begin{aligned}
& \mathrm{Co}_{2 a}=\mathrm{SO}_{2 a} \cdot \mathrm{Hb} \cdot 1,39(100 \cdot a) / \mathrm{Patm} \cdot \mathrm{pO}_{2 a} \\
& \mathrm{Co}_{2 v}=\mathrm{SO}_{2 v} \cdot \mathrm{Hb} \cdot 1,39(100 \cdot a) / \mathrm{Patm} \cdot \mathrm{pO}_{2 v},
\end{aligned}
$$

where $\mathrm{Hb}$ - hemoglobin; $\mathrm{SO}_{2 a}, \mathrm{SO}_{2 v}, \%$ - oxygen saturation in arterial $(a)$ and venous $(v)$ blood; $p \mathrm{O}_{2 a}, p \mathrm{O}_{2 v}, \mathrm{~mm} \mathrm{Hg}$ - partial pressure of oxygen in arterial (a) and venous ( $v$ ) blood; $a=$ 0,023 - a coefficient that depends on the temperature at which the blood oxygen content was measured, $t=37^{\circ} \mathrm{C} ; \mathrm{Patm}=760 \mathrm{~mm} \mathrm{Hg}$ - atmospheric pressure.

For the data processing were used the special algorithms of cluster analysis (Nastenko, 1996), correlation and regression analysis and variation statistics as well.

A detailed analysis of the dependencies and the corresponding regression equations are given in (Nastenko, e.a., 2000, 2001).

\subsection{Empiric results}

As the first step the interrelationships between systemic oxygen delivery $\left(I D O_{2}\right)$ and consumption $\left(\mathrm{IVO}_{2}\right)$ (Nastenko, e.a., 2000, 2001) in intact cardiovascular system were studied (fig.1).

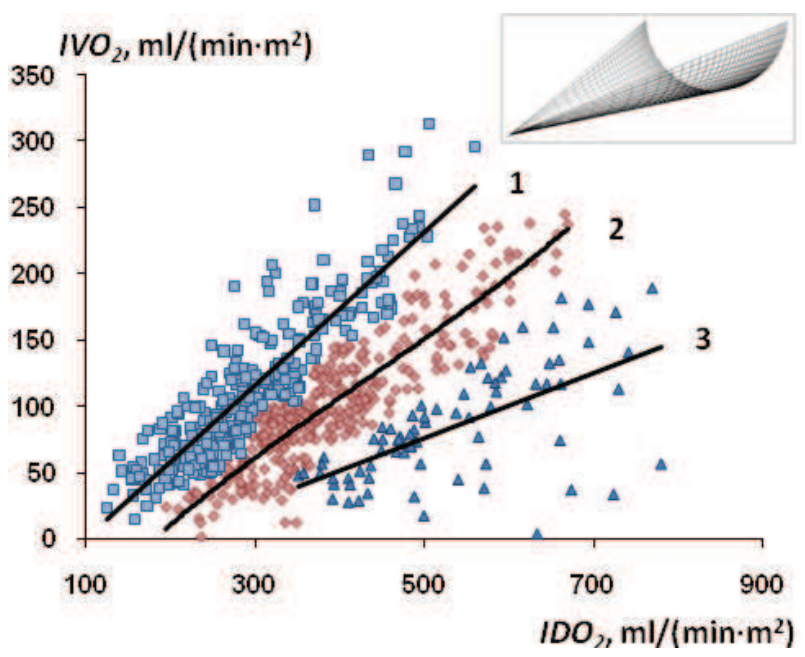

Fig. 1. Dependencies of systemic oxygen consumption $\left(\mathrm{IVO}_{2}\right)$ on its delivery $\left(\mathrm{IDO}_{2}\right)$. 1 - heart failure; 2 - normal regulation; 3 - heart hyperfunction.

With application of the special cluster analysis (Nastenko, 1996) we obtained the family of three dependencies $\mathrm{IVO}_{2}\left(\mathrm{IDO}_{2}\right)$ (fig.1). Their regression equations are presented below: 


$$
\begin{gathered}
I V O_{2}=0,578 \cdot I D O_{2}-57,27 ; R=0,89, N=293 ; p<0,001 ; \\
I V O_{2}=0,456 \cdot I D O_{2}-75,90 ; R=0,90, N=317 ; p<0,001 ; \\
I V O_{2}=0,317 \cdot I D O_{2}-64,05 ; R=0,89, N=76 ; p<0,001 .
\end{gathered}
$$

We considered the mean values of system hemodynamic parameters and of gas content in arterial and venous blood for integrated estimation of parameters regulatory relations which generated the observing dependencies (Table 1).

The mean values of arterial $(M A P)$ and central venous $(C V P)$ pressures were approximately constant.

The differences of oxygen consumption $\left(\mathrm{IVO}_{2}\right)$ at the same oxygen delivery $\left(\mathrm{IDO}_{2}\right)$ can be explained by changes of ratio of nutritive and of shunting blood flow fractions.

Along every dependency $\mathrm{IVO}_{2} ; \mathrm{IDO}_{2}$ were strongly correlated with $\mathrm{CI}$ (hydrodynamic opening of micro vessels at approximately the constant arterial pressure).

At the same time at fixed value of $I D O_{2}$ higher values of $I V O_{2}$ were observed at lower values of $\mathrm{CI}$ and correspondingly at higher systemic vascular resistance index (SVRI) (Table 1).

\begin{tabular}{|c|c|c|c|c|c|c|c|}
\hline \multirow{3}{*}{$\begin{array}{c}\text { T } \\
\text { № }\end{array}$} & \multirow{3}{*}{ Parameter } & \multicolumn{6}{|c|}{ Number of dependency and observations quantity } \\
\hline & & \multicolumn{2}{|c|}{$\begin{array}{c}(1) \\
N=293 \text { obs. }\end{array}$} & \multicolumn{2}{|c|}{$\begin{array}{c}(2) \\
N=317 \text { obs. }\end{array}$} & \multicolumn{2}{|c|}{$\begin{array}{c}(3) \\
N=76 \text { obs. }\end{array}$} \\
\hline & & $M$ & $\pm m$ & $M$ & $\pm m$ & $M$ & $\pm m$ \\
\hline 1 & $H R, \min ^{-1}$ & 92,5 & 1,0 & 92,1 & 1,0 & $96,3^{*}$ & 1,9 \\
\hline 2 & $C I, 1 / \mathrm{min} / \mathrm{m}^{2}$ & 1,77 & 0,03 & $2,26^{*}$ & 0,03 & $3,02 *$ & 0,09 \\
\hline 3 & $S V R I$, dyn $\cdot \mathrm{sec} \cdot \mathrm{sm}^{-5} \cdot \mathrm{m}^{2}$ & 3580 & 74 & $2708^{*}$ & 46 & $1996^{*}$ & 63 \\
\hline 4 & $M A P, \mathrm{~mm} \mathrm{Hg}$ & 78,5 & 0,7 & 78,0 & 0,7 & 77,7 & 1,2 \\
\hline 5 & $\mathrm{CVP}, \mathrm{mm} \mathrm{Hg}$ & 5,8 & 0,1 & 6,0 & 0,1 & 5,9 & 0,3 \\
\hline 6 & $\mathrm{Co}_{2 a}, \mathrm{ml} / \mathrm{dl}$ & 16,8 & 0,1 & $17,4^{*}$ & 0,1 & 17,9 & 0,2 \\
\hline 7 & $\mathrm{Co}_{2 v}, \mathrm{ml} / \mathrm{dl}$ & 10,6 & 0,1 & $13,1^{*}$ & 0,1 & $15,1^{*}$ & 0,1 \\
\hline 8 & $\Delta \mathrm{Co}_{2 a, v}, \mathrm{ml} / \mathrm{dl}$ & 6,2 & 0,1 & $4,4^{*}$ & 0,1 & $2,8^{*}$ & 0,1 \\
\hline 9 & $\mathrm{PCO}_{2 a}, \mathrm{~mm} \mathrm{Hg}$ & 35,2 & 0,4 & 34,6 & 0,3 & 33,7 & 0,7 \\
\hline 10 & $\mathrm{PCO}_{2 v}, \mathrm{~mm} \mathrm{Hg}$ & 42,3 & 0,4 & 40,6 & 0,4 & 39,2 & 0,8 \\
\hline 11 & $p H a$ & 7,42 & 0,02 & 7,43 & 0,01 & 7,44 & 0,02 \\
\hline 12 & $p H v$ & 7,36 & 0,02 & 7,37 & 0,02 & 7,38 & 0,02 \\
\hline
\end{tabular}

Low cardiac output causes the decrease of oxygen content in venous blood $\left(\mathrm{Co}_{2 v}\right)$ at approximately constant oxygen content in arterial blood $\left(\mathrm{Co}_{2 a}\right)$. Consequently the increase of

$\left.{ }^{*}\right)$ the statistical difference in comparison with parameter for previous dependency is significant $(p<$ $0,05 \ldots 0,01)$.

Table 1. Mean values of system hemodynamic and biochemical parameters. Numbers of dependencies correspond to regression equations (6)-(8) and curves 1-3, fig.1

arterio-venous gradient of oxygen content $\left(\Delta \mathrm{Co}_{2 a, v}\right)$ at low $\mathrm{CI}$ can be observed from two reasons: (i) activation of mass transfer through the capillary wall and (ii) from the activation 
of oscillations frequency of capillaries (flickering of capillaries) with decrease of cardiac index (Knyshov e.a., 2009; Nastenko e.a., 2002) and predominant flow of blood through the zones with maximum oxygen debt.

Both of these mechanisms can be simulated with cellular automata models.

\section{Cellular Automaton (CA) description}

\subsection{Theoretical preconditions of capillary network CA}

Cardiovascular system (CVS) can be considered as interaction of combination of continual (arterial flow) and discrete (capillary flow) mechanisms (Chernukh \& Alexandrov, 1984; Zveifach e.a., 974, 1977), which are studied insufficiently on present moment.

The relative regulatory autonomy of peripheral circulatory system can be simulated in more simple way by using of cellular automata models.

Changes in metabolic activity of tissues and the level of systemic blood flow causes to a change in the number of active capillaries and the duration of their active state. Each capillary is preceded by a sphincter, formed by several smooth muscle cells, which are an extension of the metarteriole muscular layer (Chernukh \& Alexandrov, 1984; Zveifach e.a., 1974, 1977).

The block-scheme of single microcirculatory unit is shown in Fig. 2. It contains the real capillaries (intended for metabolic exchange) and arterio-venous (A-V) shunt microvessels.

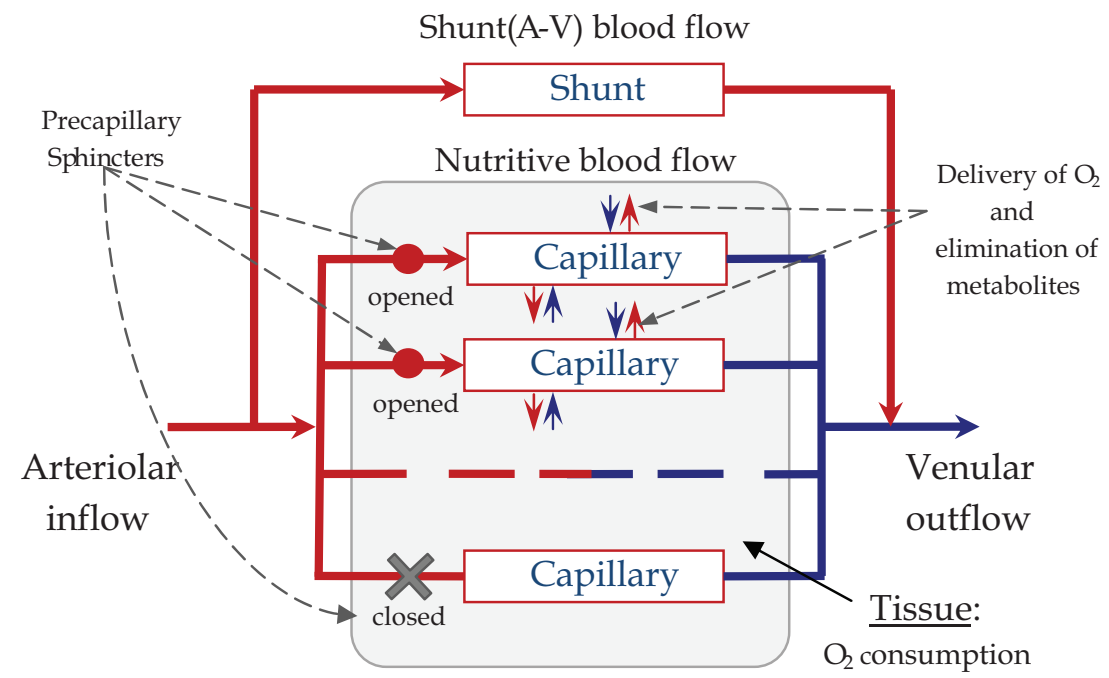

Fig. 2. Block-scheme of microcirculatory unit

At normal oxygen saturation of the surrounding tissues precapillary sphincter closes under the influence of the sympathetic nervous system (SNS), thus capillary blood flow stops (Fig.2).

The cells of tissue, adjacent to the closed capillary, produce the vazodilatory metabolites [1, $2,4]$, which block the effect of the SNS. This leads to opening of sphincters, the resumption of blood flow through the capillary, oxygen flow and excretion of metabolites through the capillary wall. The action of SNS is restored after elimination of the accumulated metabolits. 
The described principle of capillary functioning allowed us to represent the capillary as a discrete element with two states: "open" and "closed". This led to the idea of creating a model of capillary network in the form of a cellular automaton (CA).

Tissue oxygen saturation and the level of accumulation of tissue metabolites are inversely correlated. This allowed us to simulate the process of activation-deactivation of the capillaries, driving a single parameter - the "potential" of the capillary and tissue cells.

\subsection{Decision rules of capillary network cellular automaton}

The above thoughts allowed us to form the crucial principles of the microcirculatory network model in the form of cellular automaton containing two types of cells. Ones are simulating the tissue cells (carrying out metabolism) and others - with discrete states, simulating capillaries.

Consider the cross-sectional area $\Omega$ of tissues so that the central axis of the capillaries were perpendicular to the plane of the section. Idealizing the model, we assume that the central axis of the capillaries of the selected area of the tissue are parallel and located at equal distances from each other, unless otherwise indicated. To avoid edge effects we close the opposite edge of the area $\Omega$. We divide the plane into square elements of the same size. Thus, in the grid nodes we have two types of elements: tissue cells - the elements that correspond to the cells of the tissue and capillary cells - the elements corresponding to capillaries.

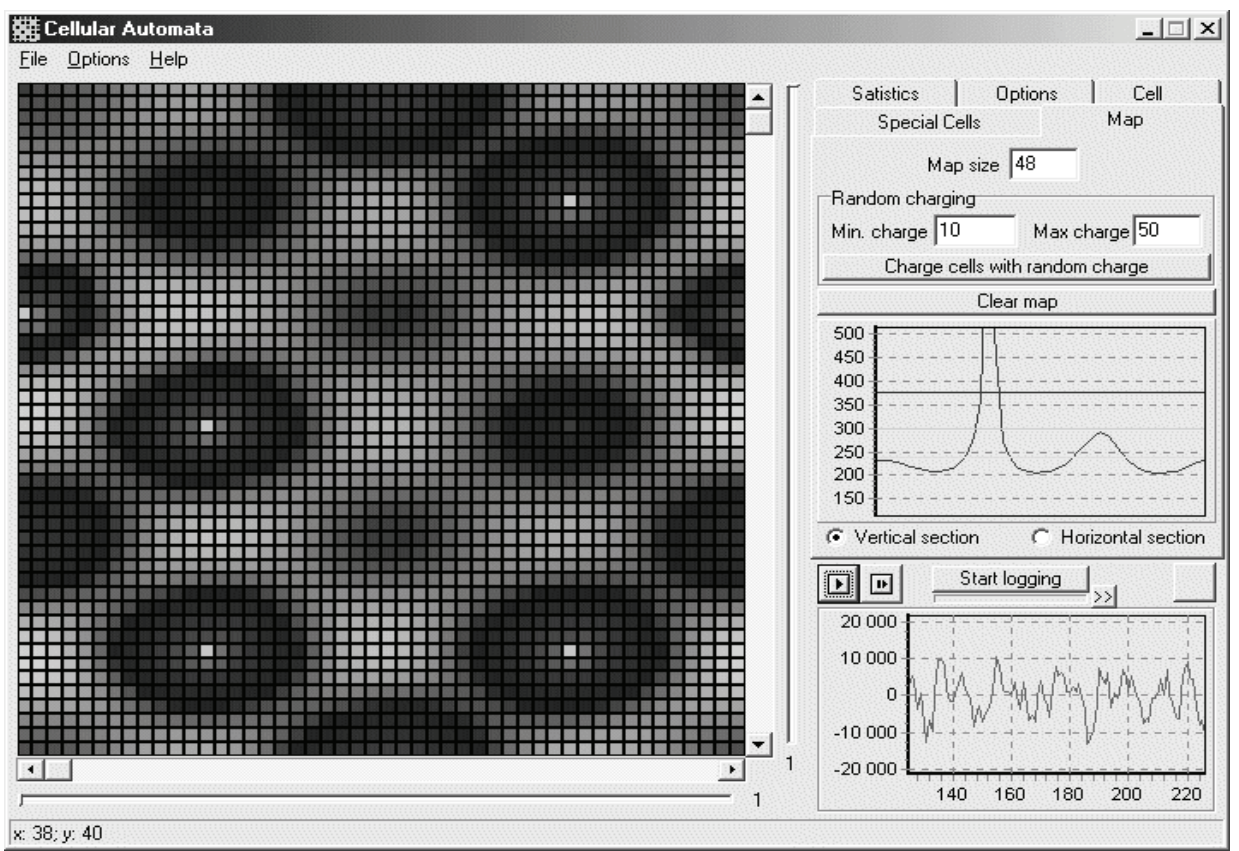

Fig. 3. The general view of cellular automaton.

Drawing an analogy with the physiological system, we introduce the quantity $z_{i j}^{t} \geq 0$ - the oxygen saturation of tissue cells at time $t$. For capillary cells we introduce the quantity $Z_{0}^{t} \geq 0$ - the concentration of oxygen in arterial blood. 
We assume that the capillary in a closed state operates as a tissue cell, and that the concentration of oxygen in an open capillary remains constant and equal to $Z_{0}$. In more general case, $Z_{0}=f(t)$ is a function.

In the following simplification we omit the existence of intercellular fluid and take a simplified scheme of the diffusion of oxygen directly into the tissue cells. Sequentially for each of the four cells we have an equation:

$$
z_{i j}^{t+1}=1 / 4\left\{z_{11}^{t}+z_{12}^{t}+z_{21}^{t}+z_{22}^{t}\right\},
$$

where $z_{i j}^{t+1}$ - the oxygen content in tissue cells (or in a closed capillary) at time $t+1 ; z_{i j}^{t}$ - the oxygen content in tissue cells (or in a closed capillary) at time $t$.

Tissue cells consume oxygen, excreting metabolites. This process is described by equation:

$$
z_{i j}^{t+1}=z_{i j}^{t}-a,
$$

where $a$ - is a value of the metabolic activity of cells, a $>0$.

Abstracting from the multifaceted complexity of the biochemical processes responsible for opening and closing of capillaries, we introduce two quantities: the threshold of capillary opening, $\Theta_{\mathrm{O}}>0$, and the threshold of capillary closing, $\Theta_{C}>0$, noting that $\Theta_{\mathrm{O}}<\Theta_{\mathrm{C}}$. Let's denote $\pi$ - the region of sensitivity to influence of vasodilatory metabolites on precapillary sphincters. $Z_{\pi}=\sum_{\pi} z_{i j}$ - the total oxygen content in all tissue cells of $\pi$.

If for a closed capillary $Z_{\pi}<\Theta_{\mathrm{O}}$, then the capillary is opened and blood oxygen saturation in it becomes $Z_{0}$ (arterial blood starts flowing through opened capillary). If for the opened capillary $Z_{\pi}>\Theta_{C}$, then the capillary is being closed and, as mentioned above, it starts to operating as a tissue cell.

The constructed model of microcirculatory network is a finite automaton. The state of matrix of cells changes abruptly, after the consequent application of decision rules to each cell of the matrix (within one iteration). Each iteration of the model contains following phases:

1. opening and closing of capillaries: for each capillary a value of $Z_{\pi}$ is calculated; then it is being compared with thresholds $\Theta_{\mathrm{O}}$ and $\Theta_{\mathrm{C}}$, and a new state of the capillary is being set according to algorithm described above;

2. the diffusion of oxygen in tissue cells (7);

3. oxygen uptake and excretion of metabolites, (8).

For simplicity of explanations, the range of values $a \in\left(0 ; a_{\max }\right]$ is called the regulatory range. Value of $a_{\max }$ corresponds to a minimum value of the metabolic activity of tissue cells, which cease to switch the status of all capillaries. In this case, depending on other parameters of the model, all the capillaries or only some of them may be opened constantly.

\section{Results of cellular automaton simulation}

This section presents the qualitative properties of the integral microcirculatory network which do not depend on the conditions of the computational experiments and characterize the systemic behavior of microcirculatory network. All parameters are presented in percents of their maximal values, i.e., qualitative analysis of characteristics is allowed.

The investigations were conducted as follows. After setting the initial conditions, when the CA passed to a quasi-steady state, all necessary parameters were registered and analyzed. 
Further, the intensity of tissue metabolic activity was changed and computational procedure was repeated.

Since the simulation pursued to study only the qualitative properties of microcirculatory network, so only relative or conventional quantitative parameters of the capillary network functioning were used.

\subsection{Static characteristics of the capillary network}

In the computational experiments we obtained integrational depencies of the following indices on the metabolic activity of tissue cells (Fig. 4): total capillary blood flow (i.e., the number of open capillaries), the average oxygen saturation of tissue cells, the number of capillaries, which are opened and closed during one iteration.

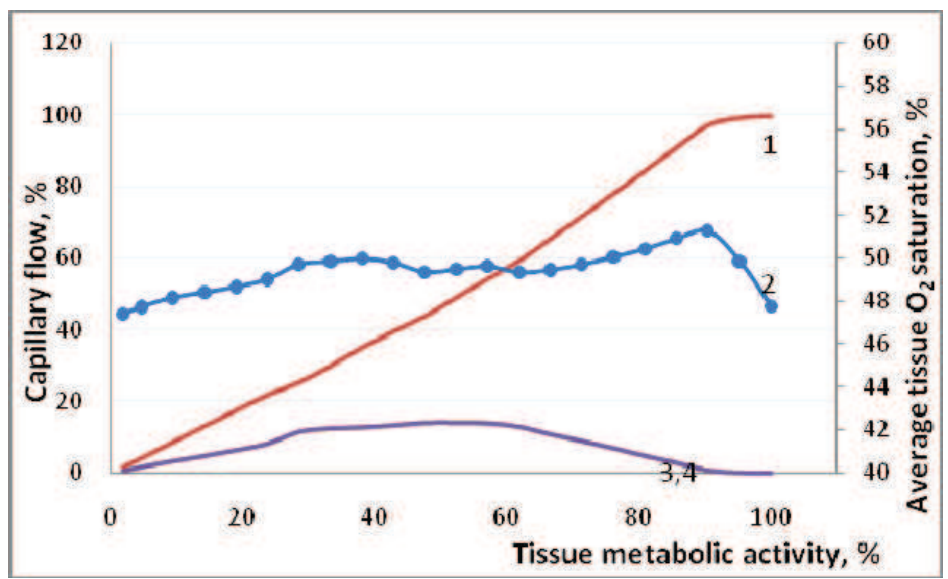

Fig. 4. Integral characteristics of capillary network dependent on tissue cells metabolic activity, represented in percents of maximum metabolic activity. 1 - capillary flow; 2 - tissue oxygen saturation; 3,4 - number of flickering capillaries (opened and closed during one iteration of change the state of all CA cells).

The number of open capillaries is linearly related to the metabolic activity of tissue cells (Fig. 3 , curve 1). The total blood flow in the capillary network is equal to the amount of blood flow through active capillaries, whose number is determined by the current metabolic activity of tissue. Linear relation between capillary blood flow and metabolic activity of tissues is in good agreement with the linear dependence of oxygen delivery and consumption, obtained from the clinical data (Fig. 1).

The average value of oxygen saturation of tissue cells $\left(z_{i j, c p}\right)$ varies slightly in the region $(0,46 ; 0,54)$ in the range $\left(0 ; 0,9 a_{\max }\right)$ of metabolic activity (see Fig. 3, curve 2$)$. This indicates the stability of the model to changes in metabolic activity of tissue cells. That is a real system, which has similar properties as represented model has, supports described characteristics without special homeostatic regulatory mechanisms.

The dependency of the average number of capillaries, which open or close during one iteration, from the metabolic activity of tissue cells (Fig. 3, curves 3,4) have a maximum in the vicinity of $0,5 a_{\max }$. Note that, although within a single iteration, the number of opened and closed capillaries can vary greatly, the average values of these indices are almost 
identical. It should also be noted that for values $a>0,5 a_{\max }$ the average number of capillaries, which changed their status, decrease due to the fact that some of the capillaries remain open permanently.

The results show high adaptability of microvascular network to changes of metabolic activity in individual organ or whole organism, which allows the homeostatic maintenance of vital balance of oxygen and metabolites in tissues.

\subsection{Investigation of the influence of density of capillary network on the magnitude of the regulatory range of oxygen transport}

Age development of a living organism is associated with varying level of tissue "capillarization" in different age periods (growing up, adulthood and aging). So, the number of capillaries per unit volume of tissue or per cross-sectional area can vary substantially. For example, aging is associated with the so-called reduction of the micro vascular network, often due to a sclerotic or other type of its arterial branches damage.

Therefore, it seems to be interesting to obtain the relation between density of capillary network (capillary/tissue cells ratio) and the value of the maximum possible tissue metabolic request which can be satisfied.

In other words, we studied the effect of the of capillary network density to the width of the regulatory range.

\subsubsection{Computational experiments conditions}

Cellular automata parameters were as following. It was used a matrix of 96x96 cells, closed in the torus, and three variants of the location of the capillaries among tissue cells (step on $X$ $\mathrm{x}$ step on Y x pitch vertical displacement): Option 1 - 6x2x3; Option $2-12 \times 4 \times 6$ and Option 3 $24 \times 8 \times 12$.

\subsubsection{Results of simulations}

The relative difference of the opening and closing thresholds of the capillaries was $10 \%$ of their mean value. Other parameters were the same as previously used.

Tissue metabolic activity were increased step-by-step after each recording of parameters performed in quasi-steady state of CA.

Computation experiment was terminated when the average value of tissue cells saturation began to decrease, and all capillaries became opened.

Simulation results for three types of capillary network density shown in Fig.5. At submaximal values of tissues metabolic activities it is observed accelerated growth of capillary blood flow.

Curves had the shape of a swan or a half loop of hysteresis. Attention is drawn to a sharp narrowing of the range of possible metabolic activity at the most "rarefied" capillary network (curve 1, Fig. 5).

With high accuracy, the dependencies were approximated by power polynomials of grade $3-4, R^{2}>0,99$. For each dependency, they are placed from up to down according to the numbering in Fig. 5.

The next question, which was subjected to the study, is as follows: how is the width of the range of possible dissipation depends on a ratio of the total numbers of capillary $\left(N_{c a p}\right)$ and tissue $\left(N_{\text {tis }}\right)$ cells $-N_{\text {cap }} / N_{\text {tis. }}$. 
For experiment conditions described above, the correlation between the $N_{\text {cap }} / N_{\text {tis }}$ ratio and maximum possible tissue metabolic activity is linear. Its regression equation is also represented on Fig.6.

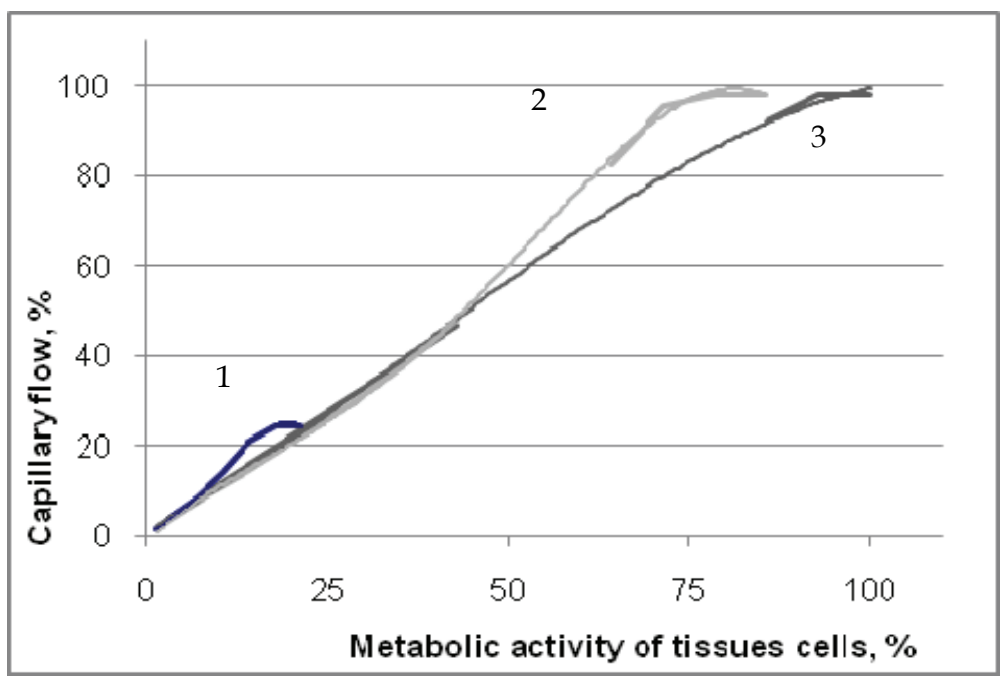

Fig. 5. Dependency of capillary blood flow on the magnitude of the metabolic activity for the

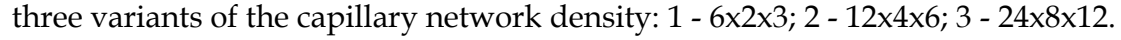

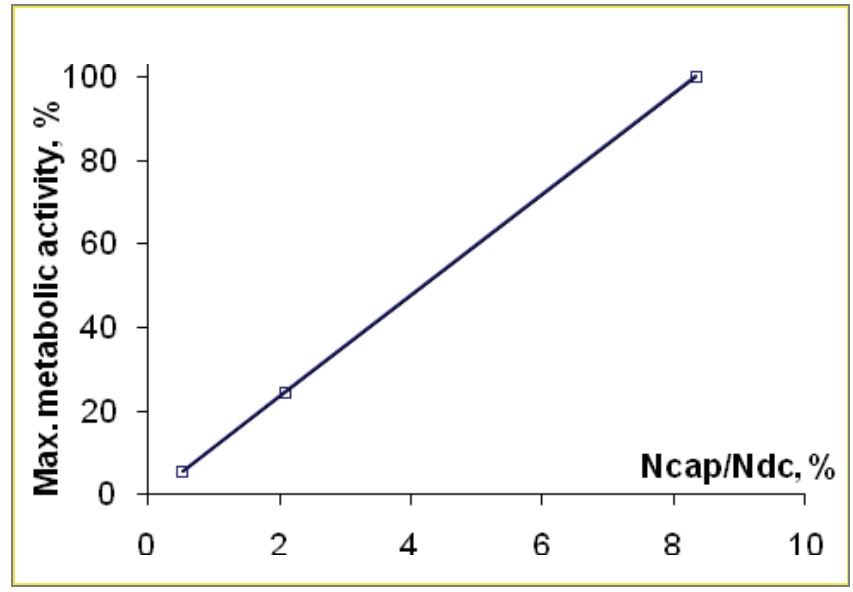

Fig. 6. Dependency of maximum possible tissue metabolic activity on the ratio of the capillary $\left(N_{c a p}\right)$ and dissipative $\left(N_{t i s}\right)$ cells $-N_{c a p} / N_{t i s}$. 
Results of computational experiments suggest that at the age-related reduction of microcirculatory network, i.e. at reducing the tissue capillarization the metabolic request, which can be satisfied, decreases linearly. Conversely, when organism is growing up, the intensive development of microcirculatory networks can lead to an increase the width of the range of possible tissue metabolic activity. Apparently, this is one of explanation of the fact that the top sports results can be achieved at a young age. With ageing the physical ability of an organism decreases quite rapidly, due to decrease of tissues capillarization.

Similar arguments can be made with respect to coronary heart disease, when the rate of development of coronary arteries lesions determines the rate of progression of heart failure. Conversely, the intensity of revascularization after acute myocardial infarction may determine the degree of restoration of functional ability of the heart.

\subsection{Dynamic properties of capillary blood flow and tissue oxygenation. Simulation results}

Cellular automaton belongs to the critically self-organized systems (Bak e.a., 1987, 1996), with varying degrees of dynamic self-organization.

Depending on the computational experiment conditions, the capillary network demonstrates one of three types of functional self-organization:

- Subcritical: the capillaries are opened and closed at random time moment (selforganization is absent);

- Critical: joint regular and random distribution of open capillaries (the system goes from self-organized into a chaotic state and vice versa);

- Supercritical: open capillaries form a regular, lattice structures, in which the capillaries are or always open or rhythmically oscillate (the system is stable self-organized).

The forms of oscillations of capillary flow and tissue oxygen saturation obtained from CA simulations are presented on fig. 5. The wide range of its oscillation properties allows attributing it to the fourth class, characterized the most diversive, most complex behavior (Wolfram, 1984) and consequently most adaptive to changes of external and internal conditions.

\subsection{Thresholds of opening and closing of capillaries}

In available information resources we did not find any data about the level at which tissue oxygen saturation and at what concentration of tissue metabolites the activation and deactivation of the capillaries is occured, wheather these values are constant or variable. CA simulation allows to objectify the whole range of the capillary network behavior and to compare the results with the real capillary system functioning.

The purpose of this section was to study the influence of difference of opening and closing capillary thresholds on the formation of capillary blood flow oscillatory properties at different levels of metabolic activity of tissues.

It should be noted that there is no physical analog of the quantity "verge of discovery" or "closure threshold" of the capillary. Physically, these values represented by a combination of factors and various physical characteristics that affect opening and closing of precapillary sphincters. In general, these values may change in time. In ongoing studies, we identify only one value which determines the state of capillary (opened/closed) - the number of metabolites accumulated in the tissues in the neighborhood of exact capillary. 

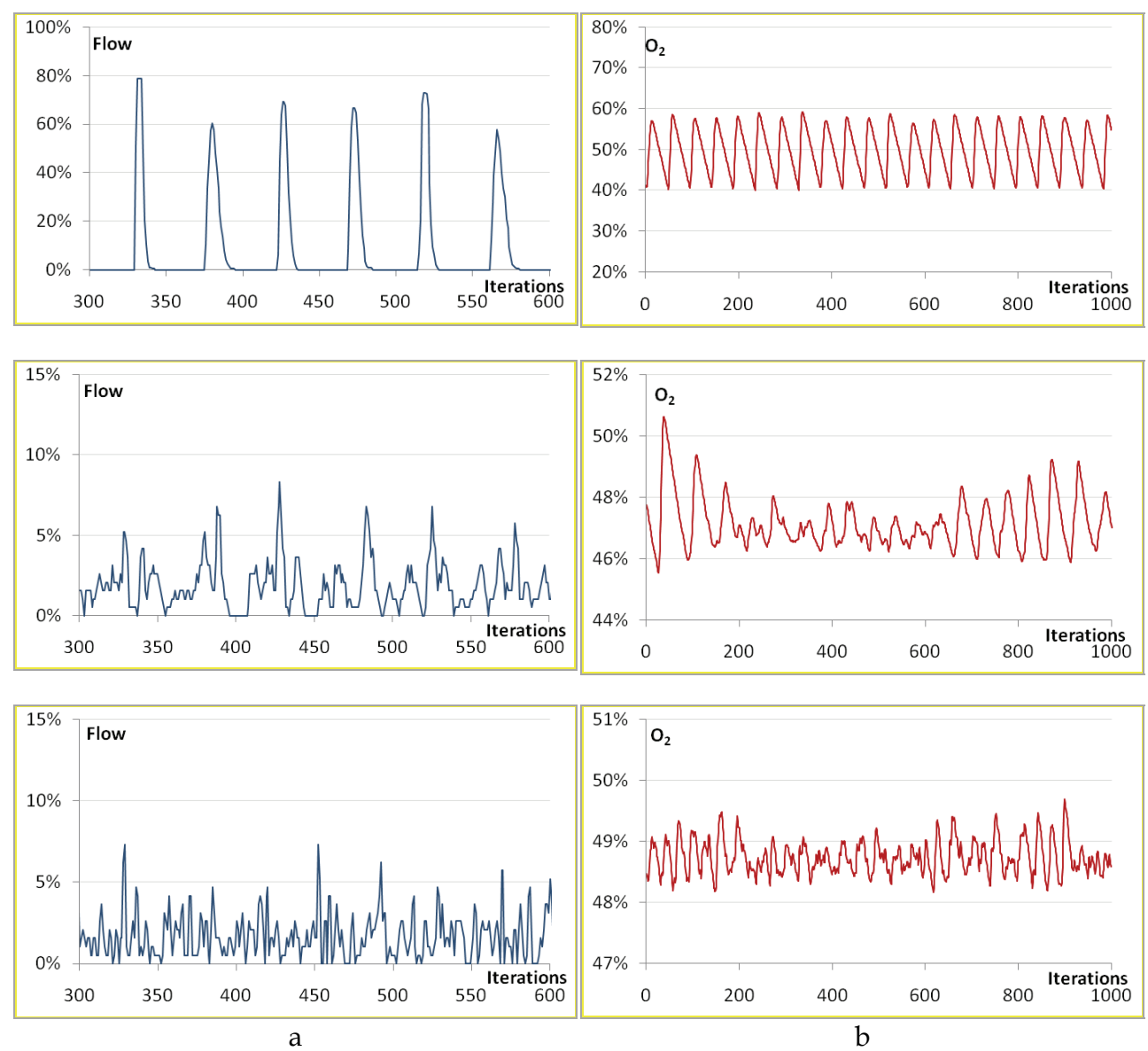

Fig. 7. The range of oscillation properties of capillary flow (a) and tissue oxygen saturation (b) obtained from CA simulations.

\subsubsection{Simulation results}

During the study we investigated the static properties of the CA - the average oxygen saturation of tissue cells, percentage of opened capillary cells (capillary blood flow); and dynamic properties as well - the percentage of capillary cells, which opened or closed during each iteration.

Tissues metabolic activity was calculated as a percentage of the maximum possible value. Differences of thresholds of capillary opening and closing were calculated as a percentage of their average value.

The average percentage of opened capillaries (of the total), depending on the tissue metabolic activity and the difference between the opening and closing of the thresholds presented in Fig. 8. 
The average value of capillary blood flow is linearly dependent on tissue metabolic activity for all differences of capillary opening and closing thresholds. With increasing these difference the average number of opened capillaries increases by $20-38 \%$ at a constant metabolic activity of tissues.

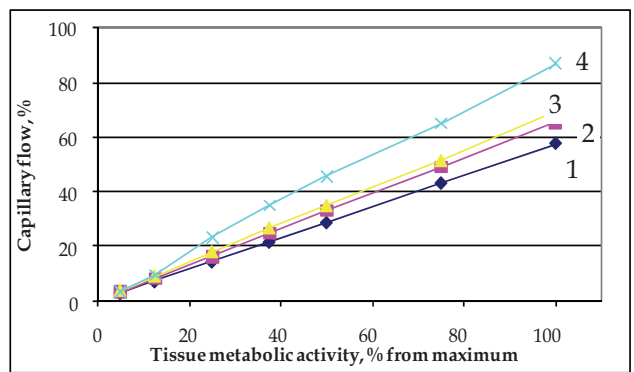

a

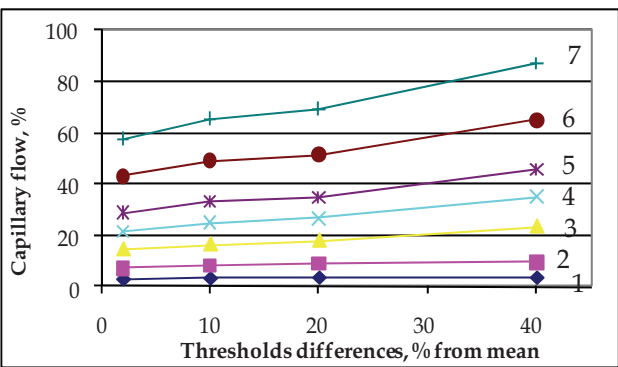

b

Fig. 8. The dependencies of capillary flow on: a - tissue metabolic activity; b - capillary opening and closing thresholds differece.

The average number of opened capillaries equal to average number of closed capillaries. Despite this a different number of capillaries opens and closes at a time (the difference reaches $25-30 \%$ of total), which causes additional fluctuations of blood flow in the capillary network.For these terms of computational experiment, the average number of opened capillaries is equivalent to the value of capillary blood flow.

For every difference of capillaries opening and closing thresholds the depencies of capillary flow on the tissue metabolic activity, as seen in Fig. 8,a are linear. The family of capillary flow curves formed by changes of capillaries opening and closing thresholds difference also was close to linear, Fig. 8,b. At the same metabolic activity of tissues, the capillary blood flow increases with increase of thresholds difference, Fig. 8,a. This can be explained by the longer time required to reach the necessary tissue oxygen saturation, that is more inert characteristics of the system.

The foregoing is confirmed by the family of curves Fig.1,b. At constant metabolic activity of tissues within each of the dependencies the capillary blood flow is than higher, than greater the difference between thresholds. This pattern is most clearly seen at high metabolic activity of tissues (Fig. 1,b, curves 1-5 from top to bottom) and almost not visible at low (Fig. $1 \mathrm{~b}$, two lowest dependencies).

It is also interesting the answer to the question, what is the percentage of flickering capillaries relative to the average number of active, in other words, what is the ratio of the dynamic (redistributing blood flow by opening and closing some part of capillaries) and the static components of the capillary blood flow. The results are presented on Fig.9.

For a small (up to $2 \%$ of the mean) difference of capillaries opening and closing thresholds the number of flickering capillaries is constantly equal to $100 \%$. Some group of them opens and the same group is closing. This leads the most dynamic redistribution of blood flow to areas of tissue with the lowest oxygen saturation.

The number of flickering capillaries rapidly decreases with increasing of the threshold difference, Fig.9,b. 

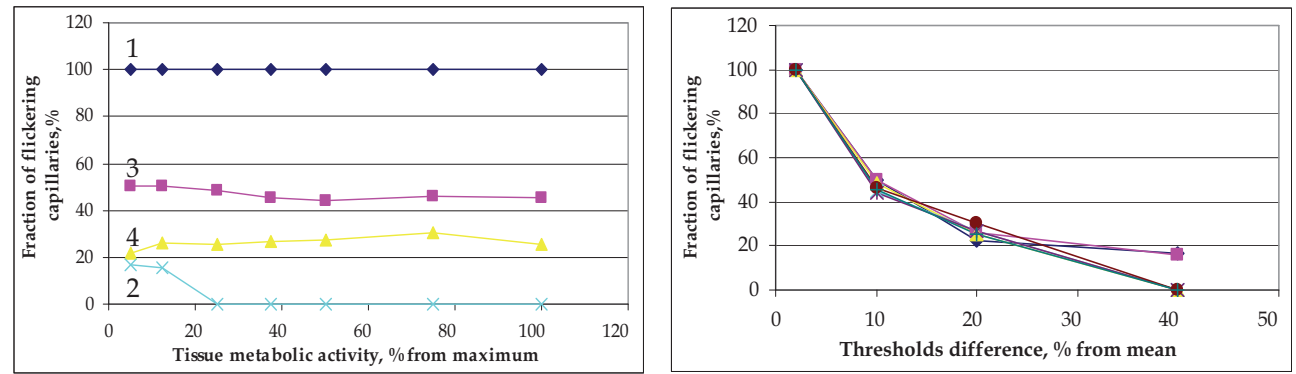

Fig. 9. Fraction of flickering capillaries, $\%$ on: a - tissue metabolic activity; b - opening and closing thresholds difference.

When the difference between the thresholds is equal to $10 \%$ on average of active, only the $50 \%$ of capillaries are opening and closing. With further increase of the thresholds difference the $22 \%$ and $16 \%$ of capillaries are flickering.

With increasing of the thresholds difference the number of flickering capillaries decreases in a hyperbolic law. Zero values indicate that the flickering stops and active capillaries become permanently opened.

Thus, the increase of thresholds difference may cause the deterioration of capillary flow redistribution.
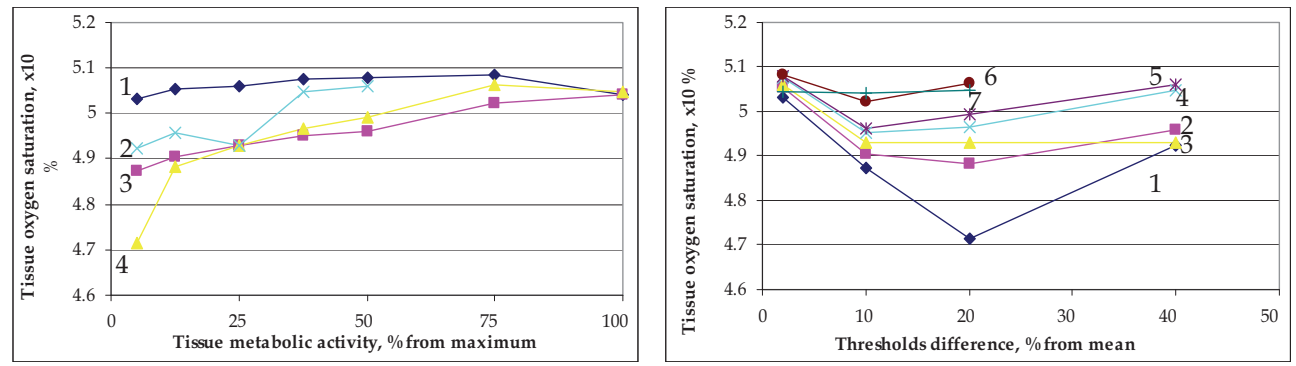

Fig. 10. The dependencies the average tissue oxygen saturation, $\%$ on: a - tissue metabolic activity; $\mathrm{b}$ - opening and closing thresholds difference.

The system "capillaries-tissue" is characterized by the following peculiarity, Fig.9,a. At a constant thresholds difference the number of flickering capillaries is constant, regardless of the metabolic activity of tissues.

For a small difference thresholds almost all capillaries are flickering. With increasing of the thresholds difference up to $10 \%$ of average number of active, the fraction of flickering capillaries varies between $42-55 \%$ of those active. With further increasing of the thresholds difference the number of flickering capillaries is reduced to zero. That is, the redistribution of nutritive (capillary) blood flow deteriorates with increasing of difference between the thresholds. This is confirmed by the schedules presented in Fig.9,b. Number of flickering capillaries, and, respectively, fraction of redistributed nutritive flow rapidly decreases with increasing of the thresholds difference.

It is observeed some analogy with acute heart failure, accompanied by tissue hypoxia. In order to saturate the tissues with oxygen and remove tissue metabolites, it is requires more 
time in which the capillaries remain open. This situation may correspond to a large difference between thresholds of the opening and closing of capillaries.

Let's consider how the above-described functional peculiarities of capillary network influence on the tissues oxygen saturation, Fig.10,a. At the small thresholds difference the tissue oxygen saturation remains approximately constant in the entire range of metabolic activity of tissues. There is a tendency to some increase in the zone of medium metabolic activity with a gradual decrease in the area of high values of metabolic activity.

With increasing the difference of thresholds observes the tendency to increase the tissue oxygen saturation with increase of tissue metabolic activity. This dependency is even more expressed on higher magnitude of thresholds difference.

If the real capillary network has properties similar to those simulated in our investigations, for more severe conditions of organism, the conditions of oxygen delivery to tissues can be improved, due to the activation of the mechanisms of mass transfer, Fig.10,b.

This peculiarity was clearly expressed for low and medium levels of tissue metabolic activity and gradually decreases with increasing of this parameter.

\section{Cellular automaton simulations of arterial and capillary flow interactions}

Cardiovascular system (CVS) can be considering as interaction of combination of continual (arterial flow) and discrete (capillary flow) mechanisms (Chernukh \& Alexandrov, 1984; Little, 1989; Rushmer, 1976) which interactions have been studied insufficiently at present moment.

The relative regulatory autonomy of peripheral circulatory system can be simulated in more simple way with use of cellular automata models.

We based our investigation assuming that microvascular arterial bed is critically selforganized system, working on the "edge of chaos". The microvascular arterial network increases or decreases diameter of arterioles and opens more or less capillaries depending on fluctuations of blood flow and pressure.

High sensitivity of capillary network to changes of internal and external conditions as well as a wide range of its oscillatory properties and also experimental data allows to assume that oscillations of peripheral and systemic blood flow can co-interact.

The purpose of this part of investigations was to simulate interactions of capillary blood flow and systemic blood flow during the single cycle of heart contraction.

\subsection{Conditions of simulation}

1. Current level of systemic flow determines the quantity of capillaries, which can work simultaneously in this moment. But cellular automaton opens as much capillaries, as necessary to satisfy the oxygen debt, but not more than permitted.

2. A single iteration of CA equals to a time unit.

3. The quantity of possibly opened capillary cells is constant during diastole.

4. The tissue metabolic activity changes from $0 \%$ to $100 \%$ with discrete step for every numerical experiment.

5. CA opens capillary when average tissue oxygen saturation is lower than "opening threshold". The number of opened special cells is determined by conditions 1, 3 .

6. Opened capillary cells closes if an average charge of surrounding tissue cells reaches the value of "closing threshold".

7. The properties of all capillary cells and tissue cells where homogenous throughout CA. 
8. It was estimated the average oxygen saturation of tissue cells, the quantity of opened capillary cells (capillary flow), and the quantity of cells opened and closed on last iteration.

9. Form of oscillation of systemic flow was assumed to be constant in all computational experiments.

10. All parameters where recorded when CA was brought to stationary mode.

\subsection{Results of simulations}

Four types of interactions between systemic and capillary flow were found, fig.11:

a. steady state, low metabolic activity, capillary and systemic flows are not synchronized;

b. normal arterial flow - capillary and systemic flow are synchronized;

c. essentially increased arterial flow (for example, stress regulation) - the groups of capillaries open and close before the end of systole that may cause the hydrodynamic overload from the increase of local vascular resistance and can damage of endothelium of micro vessels;

d. essentially decreased arterial flow, tissue hypoxia: some capillaries do not close at the end of systole from the high concentration of vasodilatory metabolites that cause the decrease of diastolic arterial pressure.

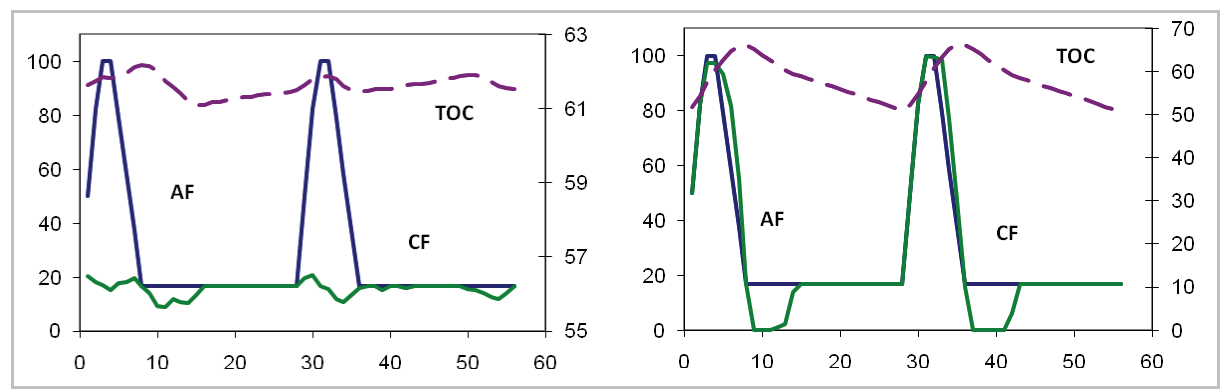

(a)

(b)

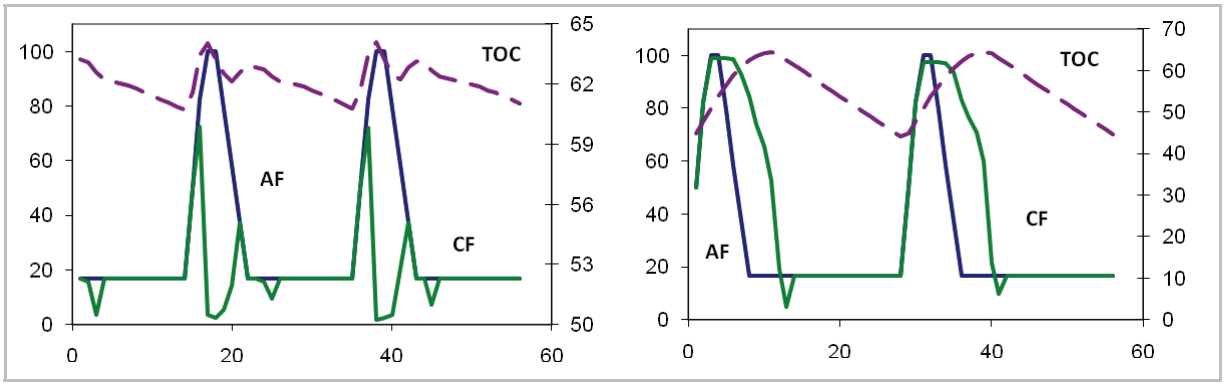

(c)

(d)

Fig. 11. Types of arterial (AF) and capillary (CF) flow interactions; oscillations of tissue oxygen consumption (TOC). Simulations with cellular automaton. 
The experimental data, presented in (Lightfoot, 1974) confirm the presupposition about the presence of peripheral and systemic flow interactions. The oscillations of blood flow in arterioles and venulaes obtained from experimental data are caused by heart beating.

\subsection{Simulation of atrial fibrillation conditions}

On this step of study, we used the real patient data with atrial fibrillation, fig.12. The systemic flow supposed to be approximately proportional to blood pressure oscillations. Then we used the CA rules pointed in previous step.

In this case at essential variation of heart rhythm and cardiac output and at certain level of tissue metabolic activity the synchronization of arterial and capillary flow was possible, fig. 13.

The capillary flow changes synchronously with arterial. The situations of surplus blood flow at the state close to basal metabolism, Fig. 13a, and when the systemic flow is higher than necessary, Fig.13, b were similar to presented on fig. 11a,c.

Presented simulations allow to suppose that capillary system functioning can be synchronized with oscillations of arterial flow.

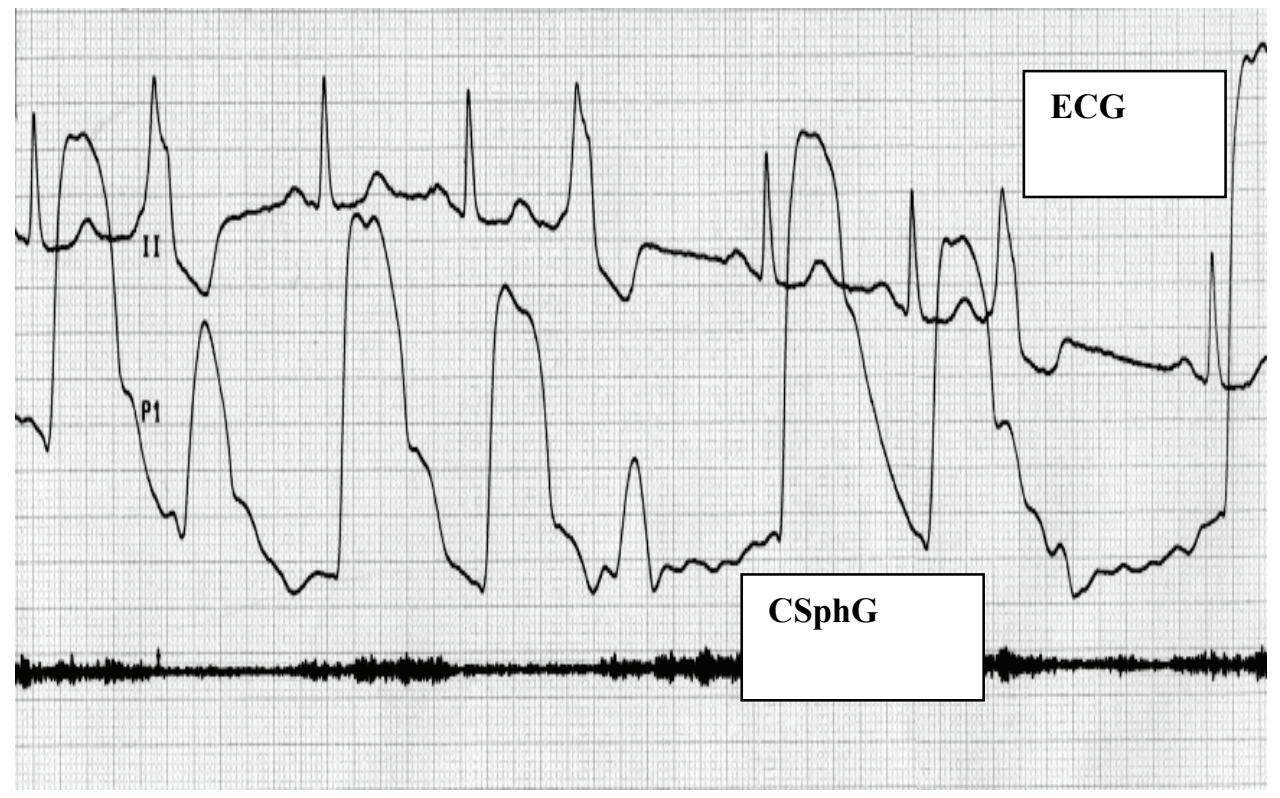

Fig. 12. Real Patient data for simulation of atrial fibrillation (Electropcardiogram - ECG and carotid shygmogram - CSphG). 


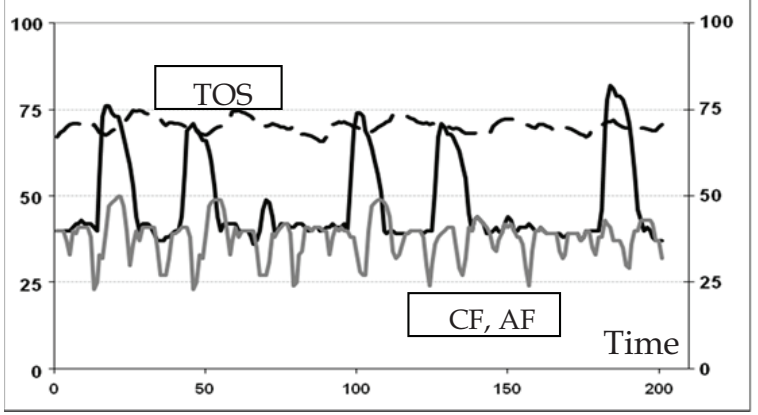

a

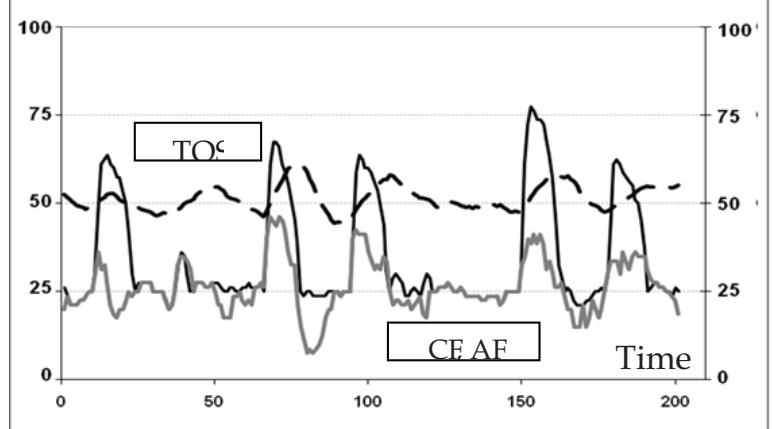

b

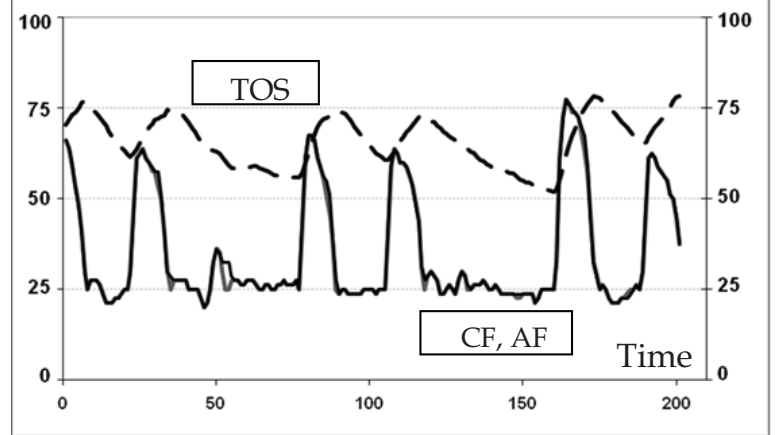

C

Fig. 13. Synchronization of arterial and capillary flow from simulations, based on real patient data with atrial fibrillation. TOS - tissue oxygen saturation; AF - arterial flow; CF - capillary blood flow. 
Different types of such interactions obtained from modeling can be a platform for planning of experimental investigations as well as for quantitative simulations of organism behavior.

\section{Conclusions and future work}

Cellular Automata Model of capillary blood flow is critically self-organized system and can be attributed to the automata of fourth class (Wolfram, 1984) that exhibit the maximum complexity and divercity of behavior. Carried out model experiments can extend our understanding of the systemic regulation of capillary blood flow and analyze a number of conditions that are difficult or impossible to obtain experimentally.

Carried out model experiments showed high adaptive properties of microcirculatory network to changes in internal and external conditions. A multiplicity of oscillatory properties of the capillary blood flow and the high complexity of behavior demonstrate the ability to synchronization the capillary and the systemic blood flow. At the same time the tissue oxygen saturation is maintained on physiologically acceptable level automatically, without any special regulatory mechanisms.

Two types of pathological interaction of capillary blood flow with systemic blood flow were obtained: for surplus systemic flow in comparison with systemic oxygen debt (stress, heart hyperfunction), as well as for insufficient blood flow (low cardiac output syndrome).

The obtained results allow understanding better the possiblities of vascular endothelium damage, which causes changes in the relations of arterial blood pressure parameters at different circulatory disorders, and on the basis of theoretical results to make the planning of the physiological and clinical studies.

In future we are plannig to use the obtained data for development of systems for clinical assessment of circulatory disorders as the violation of interactions of microcirculatory system and central hemodynamics, in particular - to estimate the pathological changes of blood pressure parameters, and on this basis to develop new approaches to the assessment of circulatory disorders and estimation of the effectiveness of therapy.

Cellural automaton models of microcirculatory system can be important component for systemic circulatory regulation modeling.

\section{References}

Achakri H., Rachev A., Stergiopulos N., Meister J.J. A theoretical investigation of low frequency diameter oscillations of muscular arteries. // Ann. Biomed. Eng. 1994. Vol. 22. N 3. P. 253-263.

Bak P. How nature works: the science of self-organized criticality. - Springer-Verlag New York, Inc. 1996. - 205 p.

Bak R., Tang C., Wiesenfeld K. Self-organized criticality: an explanation of $1 / \mathrm{f}$ noise / / Phys. Rev. Lett. - 1987. Vol. 59. №4.-R 381-384.

Cavalcanti S., Ursino M. Chaotic oscillations in microvessel arterial networks. //Ann. Biomed. Eng. 1996. Vol. 24. N 1. P. 37-47.

Chernukh A.M., Alexandrov P.N. Microcyrculation.-Moscow.- Medicine, 1984.-432 p. (Rus.)

Kaplan J. Cardiac Anesthesia. // Philadelphia.-1979.-530 p.

Knyshov G., Nastenko E., Maksymenko V., Kravchuk A. Nutritive flow, shunt flow and peculiarities of microcirculation in regulation of oxygen transport // Proceed. of 10th Eur. Congr. on Extra-Corp. Circ. Technol. - Funchal, Portugal. - 2003. - P. 69-75. 
Knyshov G., Nastenko Ye., Maksymenko V., Kravchuk O., Shardukova Yu. The Interactions between Arterial and Capillary Flow. Cellular Automaton Simulations of Qualitative Peculiarities.- WC 2009, IFMBE Proceedings 25/IV, - 2009. P. 572574.// www.springerlink.com

Lightfoot E. N. Transport phenomena and living systems: biomedical aspects of momentum and mass transport. New York: John Wiley and Sons. 1974. 495 p.

Little R. C., Little W. C. Physiology of the Heart and Circulation. // Year Book Med. Publ. Inc.- $1989 .-379 \mathrm{p}$.

Nastenko E., Maksymenko V., Belov Yu., Kravchuk A. Modeling of complex behaviour of the microvascular arterial network with cellular automata // Mathem. Modeling \& Computing in Biology and Medicine. 5th ESMTB Conference 2002. - Ed. By V. Capasso. - MIRIAM. - Italy. - P. 227-234.

Nastenko E.A., Maksymenko V.B., Palec B.L., Onishchenko V.F., Rysin S.V. The role of central hemodynamics in the regulation of systemic oxygen transport // Yearbook of scientific works of the Association of Cardiovascular Surgeons of Ukraine - V. 8. - 2000. P. 142-144. (Rus.)

Nastenko E.A., Maksymenko V.B., Palec B.L., Rysin S.V. Investigation of the role of peripheral vascular resistance in the optimization of system of oxygen transport in norm and at heart failure. $\backslash \backslash$ Yearbook of scientific works of the Association of Cardiovascular Surgeons of Ukraine.-2001. -VOL.9 - C. 227-231. (Rus.)

Nastenko E.A. The Use of Cluster Analysis for Partitioning Mixtures of Multidimensional Functional Characteristics of Complex Byomedical Systems.- J. of Automation and Information Sciences.-V.28,-N5-6,-1996.- P.77-83.

Naylor-Shepherd M.F., Fuchs D.W., Angaran D.M. Oxygen homeostasis: theory, measurement, and therapeutic implications. // DISCP, Ann. of Pharmacotherapy.V.24,- 1990. -P.1195-1203.

Ream A.K., Fogdall R.P. Acute cardiovascular management anesthesia and intensive care. // Philadelphia-Toronto: J.B. Lippincott Company.- 1982.-940 p.

Reeder G.D. The biochemistry and physiology of hemoglobin. // Am. Soc. of Extra-Corp. Technol., Inc., AMSECT.-Reston.- Virginia.-1986.- 250 p.

Risk Management: Risk. Sustainable development. Synergetics. - M.: - Science. - 2000.-431 p. (Rus.)

Rushmer R. F. Cardiovascular Dynamics, 4th edition, Philadelphia, W. B. Saunders Co.1976.-584 p.

Samsel R.W, Shumacker P.T. Oxygen delivery to tissues.//Eur. Respir.J., 4,-1981. P.12581267.

Wolfram S. Universality and complexity in cellular automata // Physica D. Vol.1. 1984. P. 91-125.

Wolfram S. Computation Theory of Cellular Automata. In: Theory and Application of Cellular Automata. World Scientific: Singapore. 1984. P. 189-230.

Yusupov R.M., Polonnikov R.I. Telemedicine - the new information technologies on the threshold of the XXI century.-St .- 1998.-490 p. (Rus.)

Zweifach B.W. Quantitative studies of microcirculatory structure and function III Analysis of pressure distribution in the terminal vascular bed in cat mesentery // Circulation. - Res. - 1974. - V. 34. - P. 843-857.

Zweifach B.W., Lipowsky H.H. Quantitative studies of microcirculatory structure and function. III. Microvascular hemodynamics of cat mesentery and rabbit omentum/ / Circulation Research, -V. 41.- 1977. - P. 380-390. 


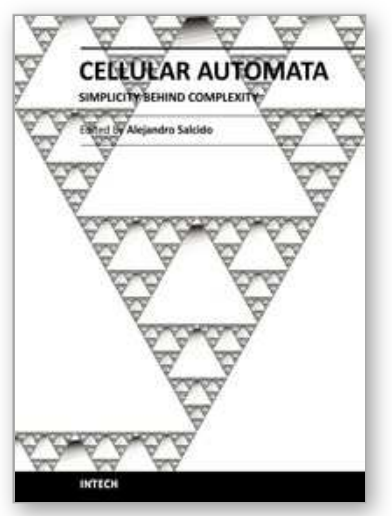

\author{
Cellular Automata - Simplicity Behind Complexity \\ Edited by Dr. Alejandro Salcido
}

ISBN 978-953-307-230-2

Hard cover, 566 pages

Publisher InTech

Published online 11, April, 2011

Published in print edition April, 2011

Cellular automata make up a class of completely discrete dynamical systems, which have became a core subject in the sciences of complexity due to their conceptual simplicity, easiness of implementation for computer simulation, and their ability to exhibit a wide variety of amazingly complex behavior. The feature of simplicity behind complexity of cellular automata has attracted the researchers' attention from a wide range of divergent fields of study of science, which extend from the exact disciplines of mathematical physics up to the social ones, and beyond. Numerous complex systems containing many discrete elements with local interactions have been and are being conveniently modelled as cellular automata. In this book, the versatility of cellular automata as models for a wide diversity of complex systems is underlined through the study of a number of outstanding problems using these innovative techniques for modelling and simulation.

\title{
How to reference
}

In order to correctly reference this scholarly work, feel free to copy and paste the following:

G. Knyshov, le. Nastenko, V. Maksymenko and O. Kravchuk (2011). Simulation of Qualitative Peculiarities of Capillary System Regulation with Cellular Automata Models, Cellular Automata - Simplicity Behind Complexity, Dr. Alejandro Salcido (Ed.), ISBN: 978-953-307-230-2, InTech, Available from:

http://www.intechopen.com/books/cellular-automata-simplicity-behind-complexity/simulation-of-qualitativepeculiarities-of-capillary-system-regulation-with-cellular-automata-models

\section{INTECH}

open science | open minds

\section{InTech Europe}

University Campus STeP Ri

Slavka Krautzeka 83/A

51000 Rijeka, Croatia

Phone: +385 (51) 770447

Fax: +385 (51) 686166

www.intechopen.com

\section{InTech China}

Unit 405, Office Block, Hotel Equatorial Shanghai

No.65, Yan An Road (West), Shanghai, 200040, China 中国上海市延安西路65号上海国际贵都大饭店办公楼405单元

Phone: +86-21-62489820

Fax: +86-21-62489821 
(C) 2011 The Author(s). Licensee IntechOpen. This chapter is distributed under the terms of the Creative Commons Attribution-NonCommercialShareAlike-3.0 License, which permits use, distribution and reproduction for non-commercial purposes, provided the original is properly cited and derivative works building on this content are distributed under the same license. 